University of Nebraska - Lincoln

DigitalCommons@University of Nebraska - Lincoln

U.S. Environmental Protection Agency Papers

U.S. Environmental Protection Agency

2000

Modeling environmental condition with indices: a case study of sustainability and soil resources

Jennie Hughes Popp

University of Arkansas - Main Campus, jhpopp@comp.uark.edu

D. Eric Hyatt

US Environmental Protection Agency

Dana Hoag

Colorado State University - Fort Collins

Follow this and additional works at: https://digitalcommons.unl.edu/usepapapers

Hughes Popp, Jennie; Hyatt, D. Eric; and Hoag, Dana, "Modeling environmental condition with indices: a case study of sustainability and soil resources" (2000). U.S. Environmental Protection Agency Papers. 106.

https://digitalcommons.unl.edu/usepapapers/106

This Article is brought to you for free and open access by the U.S. Environmental Protection Agency at DigitalCommons@University of Nebraska - Lincoln. It has been accepted for inclusion in U.S. Environmental Protection Agency Papers by an authorized administrator of DigitalCommons@University of Nebraska - Lincoln. 


\title{
Modeling environmental condition with indices: a case study of sustainability and soil resources
}

\author{
Jennie Hughes Popp ${ }^{\mathrm{a}, *}$, D. Eric Hyatt ${ }^{\mathrm{b}}$, Dana Hoag ${ }^{\mathrm{c}}$ \\ a Department of Agricultural Economics and Agribusiness, University of Arkansas, 221 Agriculture Building, Fayetteville, \\ AR 72701, USA \\ ${ }^{\mathrm{b}}$ US Environmental Protection Agency, 999 18th Street, Suite 500 (8EPR-EP), Denver, CO 80202, USA \\ c Department of Agricultural and Resource Economics, B320 Clark Building, Colorado State University, B320 Clark Building, \\ Fort Collins, CO 80523, USA
}

\begin{abstract}
The authors present a framework that illustrates how a resource quality index can be used to examine policy relevant questions regarding environmental condition, the management of a resource as a production output, and sustainability. The framework demonstrates that heterogeneous endowments of a resource can change over time in different ways. By evaluating these changes using substitution, reversibility and uncertainty criteria, we can suggest four general guidelines for managing an environmental resource in a single production process. This framework was applied in a case study to three soil types (stable, neutral and susceptible) used in agricultural production in the Midwestern United States. By evaluating the economic and environmental impacts of managing soil quality under different sustainability and profit objectives, we uncovered policy relevant information including: which soils need to be preserved; when public intervention is needed to attain sustainability; and what perceptions of sustainability may be worth pursuing at all. The accuracy of these insights is highly dependent upon the reliability of the assessment of resource quality. An index was useful in this resource assessment because it could adapt to many of the complexities of environmental condition. We offer three lessons in refining resource indicators so that they may be used in the framework to better achieve optimal resource management and a greater understanding of what sustainability really means. (C) 2000 Elsevier Science B.V. All rights reserved.
\end{abstract}

Keywords: Ecological assessments; Environmental condition; Environmental indicator; Indices; Resource management; Soil quality; Sustainability

\footnotetext{
* Corresponding author. Tel.: + 1-501-5752279; fax: + 1501-5755306.

E-mail address: jhpopp@comp.uark.edu (J.H. Popp).
}

\section{Introduction}

Sustainability, as a concept, is enigmatic. For decades, scholars across disciplines have struggled to uncover its 'true' meaning and the associated directives for resource management. Some such as Hartwick (1978) and Solow (1974) suggest that 
the 'flows' from a resource may be transformed into physical capital to produce goods and services. Others, notably Pearce and Atkinson (1993, 1995), contend that perpetuating a constant 'stock' of natural capital is the only way to achieve sustainability. These common sustainability ideologies are only two of an uncountable number of interpretations. In order to understand what is sustainable in resource management, an explicit understanding of environmental condition is required first.

Assessing environmental condition is not easy. Ecosystems are complex compared to the broad terms used to express societal goals, such as 'clean water' or 'healthy soil.' Consequently, policy makers need complex information expressed in simple terms. 'Ecological assessment' is the process of interpreting and evaluating scientific data and information for the purpose of answering policy-relevant questions about ecological resources. Environmental indicators used in the assessment process can help to describe the environmental condition and predict how natural and anthropogenic activities may alter this condition in the future. Furthermore, selecting the appropriate environmental indicator is complicated by at least three important factors: (1) concerns over excess subjectivity within the construction of indicators; (2) the ability of indicators to encompass spatial dimensions associated with resource heterogeneity and resource use; and (3) the need for indicators to trace change in resource quality over time. The assessment process adds 'definition' and objectivity when trying to convert valueladen concepts (such as 'sustainability') into measurable endpoints (Hyatt and Hoag, 1997).

The purpose of this report is to demonstrate that in at least some cases, indices of complex systems can be used to evaluate the sustainability of a natural resource. Concepts about environmental indicators and sustainability were reviewed in the existing soils, sociology, development, ecology and economic literature. Then a resource management framework was developed and applied to an actual resource in a real production setting. While many authors have acknowledged the need for an extensive study of sustainability, few if any have been able to convincingly demon- strate sustainability concepts in an empirical setting. Most real world problems are too complex. We purposely chose to limit our scope to one very important resource, soil, in order to find a problem uncomplicated enough to explore several concepts of sustainability.

Our research findings illustrate how an index of resource quality (soil quality in this case) can be used to examine resource management and sustainability. The framework tracks economic and environmental impacts associated with how soil is managed for crop production using two ideas of sustainability: the preservation of the stock of resource quality and the preservation of resource flows (the output of economic and environmental services over time).

This report begins with a summary of the framework. An application of the framework to three types of soil endowments in an empirical example follows. We conclude with a number of lessons that we have learned regarding the relevance of this research and how close we are to modeling environmental condition and targeting sustainability.

\section{A framework for examining the environmental condition in a production setting}

The environmental condition of natural capital (resource) is only one of many factors that contributes to economic and environmental production processes valued by society. For example, the availability of safe drinking water is related to both the quality of the water source, and to purification technologies and water storage/transportation facilities. Therefore, to truly appreciate a manager's ability to maintain a given production process while targeting some sustainability ideal, one must examine how the resource interacts with other inputs in the appropriate production setting.

Managers of a natural resource can use, maintain, or build their resource endowment over time thereby affecting their ability to produce a given output in the future. By borrowing from microeconomic theory (e.g. Nicholson, 1992, and Varian, 1992) we illustrate how management deci- 

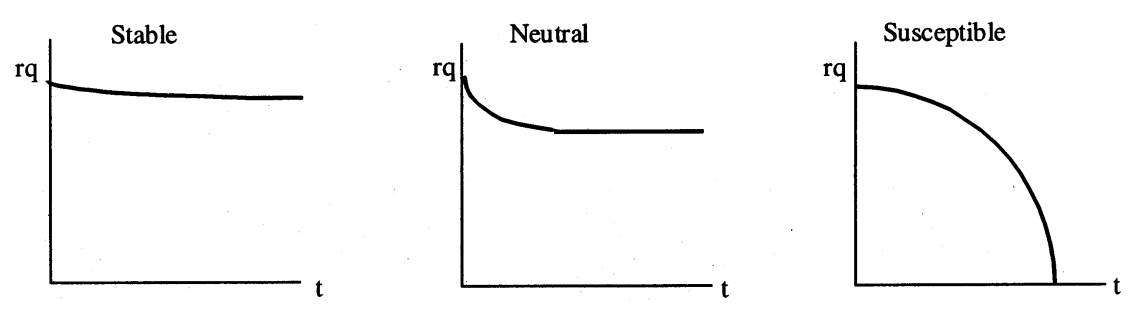

Fig. 1. Three types of resource quality degradation.

sions can alter environmental condition and influence a manager's ability to reach production, profit and/or sustainability objectives. The model is based on four assumptions: (1) producers are endowed with a resource of a given quality; (2) input and output suppliers face perfectly competitive markets; (3) firms are profit maximizers; and (4) the production function is strictly concave, that is, the function has only one maximum point.

A firm may use either or both of two factor inputs, $x_{1}$ and $x_{2}$ to produce an output, $Y$ :

$Y=f\left(x_{1}, x_{2}\right)$

Production is also a function of the firm's endowment of a natural productivity, resource quality, rq:

$$
Y=f\left(x_{1}, x_{2}, \text { rq }\right)
$$

The rq is a special input in production because producers cannot control their initial endowment of rq nor, can they initially change it. This rq contributes to the effectiveness of the added inputs and, therefore, has important implications for the choice of input mix.

\subsection{The alteration of environmental condition}

In any production process, an endowment of rq is not constant, it changes over time. Resource quality can increase, decrease or remain fairly stable over time. The case of a decreasing resource poses interesting questions for sustainability.

A resource may depreciate through two means. First, it can change through the normal operations of the natural environment. Eutrification of a lake, for example, is a natural process. There are many paths of depreciation a resource can take but three general cases (stable, neutral and suscep- tible endowments) are illustrated in Fig. 1. 'Stable' endowments are relatively immune to natural degradation and hold their quality over time. 'Susceptible' endowments are highly sensitive to depreciation, quality will fall continuously until it (asymptotically or actually) reaches zero. Somewhere in between exist 'neutral' endowments that initially succumb to quality losses through degradation but eventually reach a lower yet steady state of quality over time. When rq is used in a production process, the associated losses of output could mirror these same paths. Each path also has implications for sustainability.

Humans may influence rq change by using inputs that slow or accelerate degradation. Walking off the paved path along a lake could dislodge bank soils pushing them into the water potentially providing enough added nutrients to increase the rate of plant growth and thus alter the natural eutrophication process. A resource using input, $x_{j}^{\text {ru }}$, could accelerate the decline in environmental condition shown by accelerated path 1 in Fig. 2 . A truly devastating input could crash quality as shown by accelerated path 2 . A resource conserving input, $x_{k}^{\mathrm{rc}}$, will slow the depreciation process, but may or may not have a direct impact on current production. Resource neutral inputs, $x_{i}^{\mathrm{rn}}$, do not directly effect rq. To account for the inclusion of $x_{j}^{\mathrm{ru}}$ and $x_{i}^{\mathrm{rn}}$, Eq. (1) can be rewritten as $^{1}$ :

$Y_{\mathrm{t}}=f\left(x_{i_{\mathrm{t}}}^{\mathrm{rn}}, x_{j_{\mathrm{t}}}^{\mathrm{ru}}, \mathrm{rq}_{\mathrm{t}}\right)$

where $i=1 \ldots I, j=1 \ldots J, \forall i \neq j$

\footnotetext{
${ }^{1}$ Assuming no direct impact on current production from $x_{k}^{r c}$ simplifies the model, but does not detract the discussion of environmental condition, resource management and sustainability.
} 

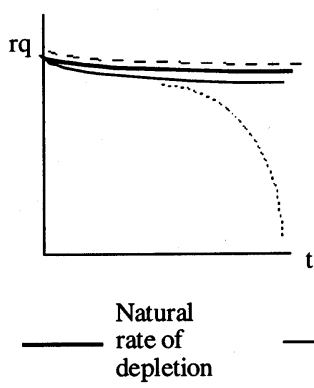

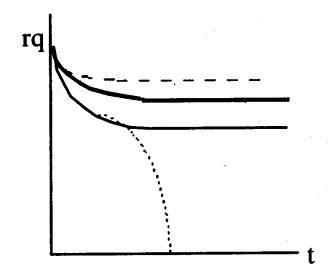

Accelerated depletion path 1
Accelerated depletion path 2

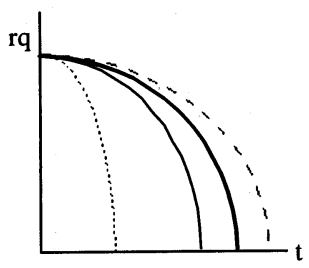

Slowed degradation due to conservation practives

Fig. 2. Impacts of natural and human activities on resource quality.

As rq changes over time, firms will adjust their input mix to maintain economic viability, and target sustainability if society desires. This may result in increased, maintained or reduced levels of output and environmental condition. These results are highly individualized based upon the type of resource endowment, the path of rq degradation and an evaluation of management options using three known sustainability criteria discussed below.

\subsection{Three criteria to evaluate sustainability of environmental condition}

Substitutability is often described by the economic concept of technical interdependence (Beattie and Taylor, 1985). It denotes how well one input may substitute for another when prices change or when one or more inputs become constrained. If rq shares a technically independent or complementary relationship with $x_{i}^{\mathrm{rn}}$ and $x_{j}^{\mathrm{ru}}$, then added use of either input cannot compensate for rq losses. Total output will decline as rq depreciates. Sustainability that requires a constant resource stock or constant resource flow is likely to be unattainable in the long run.

If rq holds a competitive relationship with $x_{j}^{\mathrm{ru}}$, then $x_{j}^{\text {ru }}$ may substitute for the decline in rq. However, since $x_{j}^{\text {ru }}$ accelerates rq degradation, the decrease in output over time may be even greater than when $x_{j}^{\text {ru }}$ and rq are complements. As long as the marginal productivity of preserving rq exceeds the marginal productivity of using $x_{j}^{\mathrm{ru}}$, a profit maximizing firm may reduce its use of $x_{j}^{\text {ru }}$ to slow the decline in rq and $Y$. If this strategy fulfils profit and the above mentioned sustainability objectives concurrently, then the optimal resource management strategy is clear.

If, however, rq and $x_{i}^{\mathrm{rn}}$ are competitive inputs, optimal management decisions can be elusive. An organization must decide whether it is better to preserve rq as long as possible, or whether it is better to substitute it away. The first case sustains the stock of rq, the second case does not. Either may meet profit maximization goals. If the second case sustains a higher income and production is not threatened by a loss of rq, then interpretations of sustainability may be at odds.

The remaining criteria, reversibility and uncertainty, are best explained together. Technically competitive relationships alone do not justify the depletion of rq. Production is plagued by uncertainty. Sudden increased use of a competitive input, or declines in rq could impose unexpected negative impacts both within and outside of the production process. Output may be dependent on a minimum level of rq, making substitution beyond a threshold level ineffective. Sustainability, no matter how defined, requires that a manager be able to adjust his mix of inputs in response to these and other unexpected occurrences. His ability to adjust depends upon his type of resource endowment and the flexibility that remains in his input decisions.

If substitutes exist as rq declines, the trade-off in their uses may follow paths as those shown in Fig. 3. Initially when $\mathrm{rq}$ is abundant and readily available a manager has a great number of input 


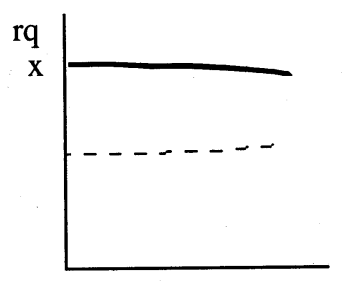

Resource quality
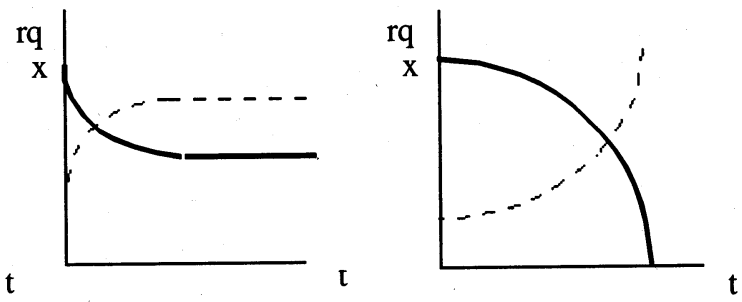

$-\ldots-\cdots$ Other inputs

Fig. 3. Trade-offs between resource quality and competitive inputs.

combinations for his production process. But as a manager depletes rq, he reduces the set of input combinations and thus his flexibility to reverse past input decisions in the future.

The framework suggests that uncertainty poses less concern in the decision to substitute away stable and neutral endowments than susceptible endowments. As illustrated in Fig. 3 when the flows of stable and neutral endowments are used in production, quality reaches a steady state at a relatively abundant level of quality and therefore both $\mathrm{rq}$ and substitutes remain available. However, the susceptible resource never reaches a steady state. As rq declines so does input mix flexibility, thereby reducing managers' abilities respond to the unexpected. Thus, there is a risk associated with using the flows of a susceptible endowment, even when substitutes exist.

\subsection{The theoretical benefits of modeling environmental condition}

This discussion shows that there are multiple benefits from modeling environmental condition (resource quality) within a framework for the management of resources used in a production setting. First, we can suggest four guidelines for managing resources optimally for one desired function or output:

- conservation is important for sustainability on neutral and susceptible soils when the resource is independent or complementary to other inputs;

- for stable resources, sustainability can be maintained without conservation if resource degradation from resource using inputs is not excessive;
- when substitutes are present, sustainability does not necessarily exclude use of stable and neutral endowments; and

- given the risks associated with irreversibility and uncertainty, it may be best to conserve susceptible resource endowments, even when substitutes exist.

Secondly sustainability is dependent upon how it is defined. In order to address a concept as value-laden as sustainability, we had to 'discretely' define our use of sustainability for the purposes of this study. This is a lesson that should be considered by all environmental managers, scientists, and decision makers, as attempts are made to convert societal values into scientific measurements - or to move from policy objectives toward the application of scientific principles and abilities.

\section{Assessing environmental condition and sustainability for soil quality management}

Soil (a dynamic, heterogeneous, living system) is formed from interactions of parent materials, weathering events and biological processes over hundreds of years. The resulting combination is a soil series, of which there are over 17000 in the United States (USDA, NRCS, 1995). The particular combination of a soil's chemical, biological and physical properties determines its ability to function for a given use. Consequently, any measure of soil quality must consider the intended use. Therefore for each soil endowment unique indicators will also likely exist for each use. We 
Stable Soil

Neutral Soil

Susceptible Soil
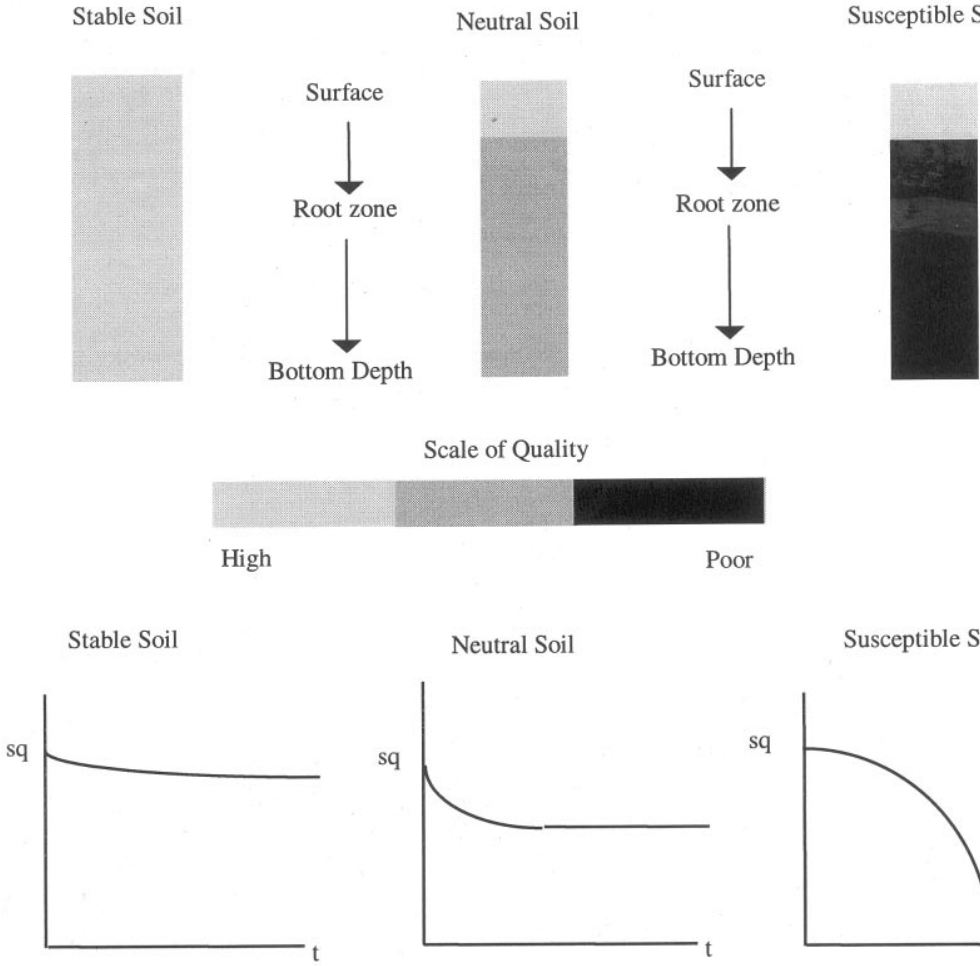

Scale of Quality

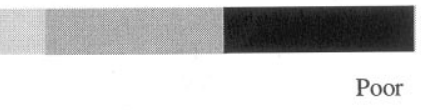

Neutral Soil

Susceptible Soil
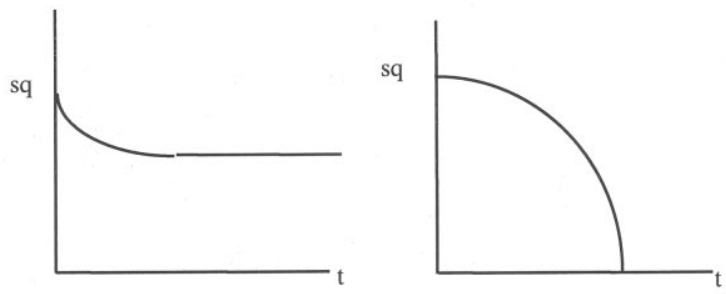

Fig. 4. Stable, neutral and susceptible soils.

focus on three types of soil endowments used in agricultural production.

\subsection{Soil quality in a production setting}

Soil quality used in crop production fits the framework well. Yield, $Y$, on a non-irrigated crop is a function of precipitation and added inputs such as tillage, fertilizer and sprayed pesticides. In addition, the farmer has an endowment of soil quality sq - equivalent to rq. He cannot control the quality of the endowment he receives, nor can he immediately change it.

Soils are subject to natural degeneration caused primarily by erosion. The depreciation rate depends upon how much change erosion brings compared to its natural regeneration rate. Three types of soil endowments in Fig. 4 described by Pierce et al. (1983) fit the paths shown in Fig. 1. Soils whose subsurface quality is similar to that of the topsoil are stable soils. As the soil erodes, quality stays relatively unchanged. For neutral soils the quality of all the lower layers is similar, but less than less than that of the top layer. Thus these soils stabilize after a period of degradation. Other soils are very susceptible to erosion because beneath a thin good quality layer on top is a very poor quality soil. Erosion reduces susceptible quality until it (asymptotically or actually) reaches zero.

Humans can influence sq degradation by altering the rate of erosion. Conventional tillage equipment (such as a moldboard plow) is a 'soil using' input. Inputs that do not have any impact on soil degradation (such as sprayed fertilizers) are 'soil neutral' inputs. Conservation practices (such as terraces) slow the rate at which sq is degraded but may or may not impact current production.

As sq changes over time, producers will attempt to adjust the input mix to maintain economic viability and target sustainability if society de- 
mands it. As sq decreases, it is expected that the use of sq and substitute inputs will follow the paths presented in Fig. 3. If a producer chooses to extensively depreciate sq in favor of a substitute, yields may be maintained temporarily, but unforeseen consequences may ensue. Short term increased demand for a substitute could cause price fluctuations or shortages in other economic sectors. Extensive degradation of sq could reduce the soil's ability to perform environmental functions (such as holding nutrients) and leaching could result. In these and other circumstances a producer may want to change his optimal input mix to include more sq. This may not be possible if sq has followed a path of irreversible decline.

\subsection{An index of soil quality}

Although consensus is growing, the properties most representative of soil quality for crop production is still debated. Table 1 lists properties commonly cited. This list is not inclusive of all sources or suggestions. It does, however, illustrate a pattern in which four soil characteristics (available water capacity, bulk density, organic matter, $\mathrm{pH}$ ) and rooting depth are often, but not exclusively, found to influence soil quality. Borrowing from Bowman and Petersen (1996), Pierce et al. (1983) and Pieri (1995), we offer an index of soil quality for agricultural production:

$\mathrm{SQI}=\sum_{i=1}^{r}\left(\mathrm{SAWC}_{i}^{*} \mathrm{SBD}_{i}^{*} \mathrm{SPH}_{i}^{*} \mathrm{SOM}_{\mathrm{i}}^{*} \mathrm{WF}_{i}\right)$

where $\mathrm{SQI}$ is a soil quality index ranging from 0 to 1 and SAWC, SBD, SPH and SOM are the sufficiency of available water capacity, of bulk density, of $\mathrm{pH}$, and of organic matter, respectively, and WF is a weighting factor associated with each $i$ th horizon, and $r$ is the number of $10-\mathrm{cm}$ horizons in the rooting depth. The decision to use an index is deliberated in Section 5.

\subsection{Dynamic model of agricultural production}

The above information was used to create a dynamic production model. The empirical dimension builds upon work by Burt (1981), Clark and Furton (1983), Hoag (1998), Pierce et al. (1983),
Saliba (1985) and Segarra and Taylor (1987). Although these researchers did not study sustainability directly, their theoretical and empirical innovations identified many of the key determinants of production and the impacts of changes in soil quality that are useful to our study.

The producer's problem is to maximize over time the discounted profits of production subject to the availability of sq and the level of the environmental byproducts of production:

$$
\begin{aligned}
\max \Pi= & \sum_{t=0}^{T}(1+r)^{-t} \\
& \left\{P_{\mathrm{y}} f\left(\mathrm{SQ}_{t}, L_{t}, \mathrm{SN}_{t}, N_{t}, P_{t}, W_{t}\right)-u_{1} L\right. \\
& \left.-u_{2} N-u_{3} P-u_{4} \mathrm{SC}\right\}
\end{aligned}
$$

subject to:

$$
\begin{aligned}
& \mathrm{SQ}_{t}=h\left(\mathrm{SQ}_{t-1}, L_{t}, \mathrm{SC}_{t}\right) \\
& \mathrm{SN}_{t}=k\left(\mathrm{SN}_{t-1}, N_{t-1}, L_{t-1}, Y_{t-1}, \mathrm{LCH}_{t-1}\right) \\
& \mathrm{LCH}_{t}=m\left(\mathrm{SN}_{t}, N_{t}, L_{t}, W_{t}, Y_{t}\right)
\end{aligned}
$$

Eq. (5) shows discounted net profit is a function of those factors that determine production soil quality (SQ), precipitation $(W)$, soil using inputs such as tillage $(L)$, and soil neutral inputs soil nitrogen, $(\mathrm{SN})$, applied nitrogen $(N)$, and sprayed pesticides $(P)$, and their associated costs where $P_{\mathrm{y}}$ is the output price, the $u_{i}$ are management practice prices, $\mathrm{SC}$ is soil conservation practices and $r$ is the discount rate. Eq. (6) explains that the stock of sq available in any period will be determined by soil quality in the previous period and current management decisions to use (tillage) or preserve (conservation practices) the soil. As indicated by Eqs. (7) and (8), a producer's management decisions influence not only the level of crop production in any year but have and environmental consequences (such as changes in soil nitrogen and leaching, LCH, levels over time) as well.

The producer's problem was empirically estimated on three susceptible, three neutral and three stable soils used in non-irrigated corn production in the states of Iowa, Missouri and Minnesota. Soil characteristics, crop production (including input use decisions), weather and economic and environmental indicator variables data were simulated for 100 years in the environmental 


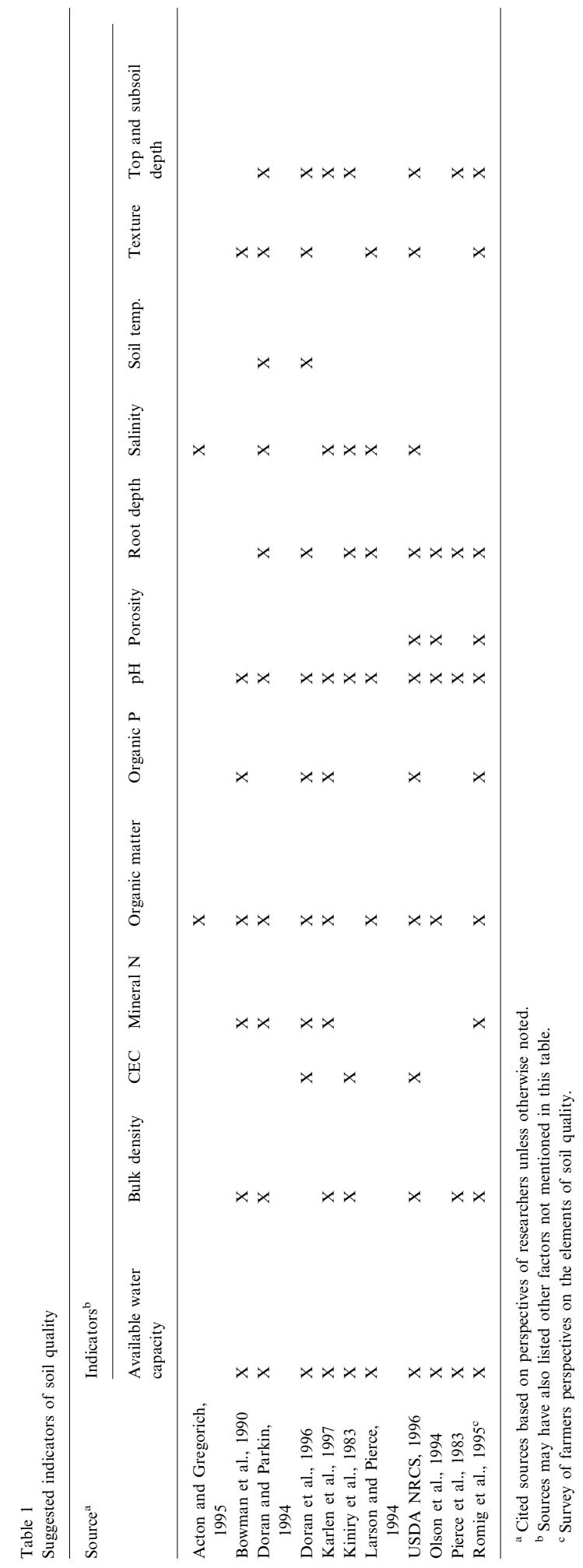


policy integrated climate (EPIC) model (Mitchell et al., 1995). A sq index for each endowment was calculated using data for the sq characteristics in Eq. (4). The fixed effect regression technique was applied to the sq index variable and other simulation panel data to estimate Eqs. (6)-(8) and the production function with Eq. (5). All estimated functions were tested and corrected for misspecification, heteroskedasticity and serial correlation (Hsaio, 1991). The adjusted $R^{2}$ values for the production function and Eqs. (6)-(8) were 0.729, 0.986, 0.999 and 0.737 , respectively ${ }^{2}$.

Once estimated, the equations were placed into general algebraic modeling system (GAMS; Brooke et al., 1992). A baseline scenario was created for each of the nine soils to track the natural paths of sq degradation over time. These paths mirrored those in Fig. 4. From the baseline, new scenarios were created so that agricultural producers had to manage sq to target one of two sustainability objectives: constant flow (or transformation) of sq into a production output over time and the preservation of soil quality stock over time. Minimum yield $(90 \%$ of that in first year of baseline) and conservation (full use of available practices) requirements were placed in the GAMS scenarios to force managers to target these objectives over the 100-year period.

\section{Empirical results}

The results of this empirical investigation provided a wealth of information regarding the impacts on environmental concerns, soil quality, stability of input mix, profit and output associated with choosing management practices to meet profit maximization and sustainability objectives. Specific results for all nine soils are not enumerated. Rather, general insights regarding optimal management techniques and targeting sustainability based on the composite findings across the three endowments within each soil type are highlighted. Four insights into the management of soil

\footnotetext{
${ }^{2}$ The fixed effect model yielded nine coefficients estimates (one for each soil) for each variable in the four equations. Given space limitations, only $R^{2}$ is reported.
}

quality for profit, resource stock and resource flow objectives are given below.

\subsection{Optimal resource management will vary across soil type}

Different soils required different management techniques. On stable soils, sq greatly contributed to production and conservation was consistently used to maintain quality. On lesser quality soils, sq was often substituted away in favor of increased fertilizer or tillage intensities. Conservation practices were occasionally used on neutral soils. But costs outweighed benefits on susceptible soils and thus conservation was only used when constant stock objectives were targeted.

\subsection{Defining sustainability is more essential on lesser quality soils}

Table 2 shows that on stable soils, all objectives were attained with the same input mix. On this soil searching for the 'true' meaning of sustainability may not be important since multiple definitions produce the same economic and environmental impacts. On neutral and susceptible soils other inputs often equaled or dominated sq in the input mix. The impacts associated with the additional use of these other inputs often placed objectives at odds. For example, increased fertilizer and tillage use needed to maintain yield (the flow condition) often resulted in sq depletion, therefore the two studied sustainability definitions were incompatible. How society defines sustainability is important on these soils because different definitions will produce differing sets of impacts.

\subsection{Technical interdependent relationships among inputs can change over time}

Sustainability conditions were not always met on susceptible soils. The inability of imperfect substitutes to compensate completely for the continued loss of sq is one reason, changes in the technically interdependent relationships among inputs is the other. 
The data for the variables in the production function best fit the transcendental form:

$$
Y=A x_{1}^{a_{1}} e^{b_{1} x_{1}} x_{2}^{a_{2}} e^{b_{2} x_{2}}
$$

At high levels of quality the production function described predominantly imperfect competitive relationships between sq and other inputs. However, at low sq levels, these relationships often turned complementary. Thus, on susceptible soils, as sq was increasingly degraded, substitution efforts became less and less effective. As shown in Fig. 5, once complementarity was established, the optimal use of a compensating input (such as fertilizer) which had been increasing through time, started to decrease since output could not be maintained. As both the compensating input and sq were less productive, yields fell and sustainability was not attained.

\subsection{Uncertainty threatens long term achievement of any objective on susceptible soils}

On all nine soils, at least two objectives were met using optimal management strategies. But not

Table 2

Compatibility of targeting three objectives on each soil

\begin{tabular}{llll}
\hline Soil $^{\mathrm{b}}$ & \multicolumn{2}{l}{ Objectives attained with the same soil management plan } & \\
\cline { 2 - 4 } & Profit maximization & $\begin{array}{l}\text { Sustainability as a constant stock } \\
\text { of soil quality }\end{array}$ & $\begin{array}{l}\text { Sustainability as a constant flow of } \\
\text { quality to production }\end{array}$ \\
\hline st-ia & $\mathrm{X}$ & $\mathrm{X}$ & $\mathrm{X}$ \\
st-mo & $\mathrm{X}$ & $\mathrm{X}$ & $\mathrm{X}$ \\
st-mn & $\mathrm{X}$ & $\mathrm{X}$ & $\mathrm{X}$ \\
n-ia & $\mathrm{X}$ & - & $\mathrm{X}$ \\
n-mo & $\mathrm{X}$ & - & $\mathrm{X}$ \\
n-mn & $\mathrm{X}$ & - & $\mathrm{X}$ \\
su-ia & - & - & $\mathrm{n} / \mathrm{a}^{\mathrm{c}}$ \\
su-mo & - & - & $\mathrm{n} / \mathrm{a}$ \\
su-mn & - & - & -
\end{tabular}

a An $\mathrm{X}$ is placed in the box of all objectives that are compatible on the particular soil.

${ }^{\mathrm{b}}$ st, $\mathrm{n}$, and su represent stable, neutral and susceptible, respectively. ia, mo and mn represent Iowa, Missouri and Minnesota, respectively.

${ }^{c}$ The conditions for meeting the constant resource flow definition of sustainability were not attained on the Iowa and Missouri soils.

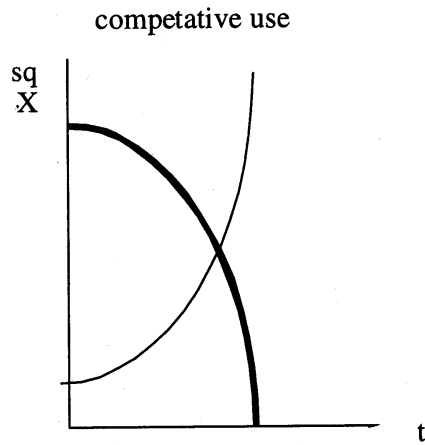

Soil quality when substitutes become complements

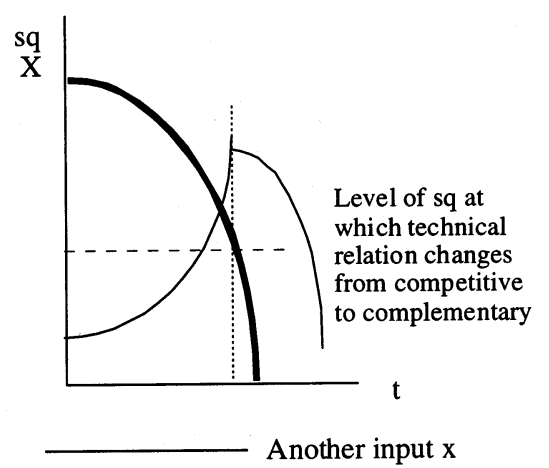

Fig. 5. Changing technically interdependent relationships. 
all strategies remained optimal when reversibility and uncertainty were considered. On stable and neutral soils, sq degenerated moderately and only limited compensation was required by added substitute inputs. If an unexpected event occurs, the manager retains his flexibility in choosing an input mix because both sq and substitutes are plentiful. However, when sq is gravely degraded as on susceptible soils, a producer might compensate with large quantities of substitutes. As quantities of good sq decline, input mix combinations are limited and may not be able to adjust to the event. Negative consequences may persist or even increase over time. Therefore, management decisions based on an inflexible mix of inputs may not truly be sustainable in the face of uncertainty.

\section{Discussion - advantages and limitations of indices in environmental indicators}

The framework presented here provides new management guidelines for heterogeneous resource endowments and other inputs used in a single production process. Inclusion of substitution, reversibility and uncertainty criteria in the evaluation have contributed to our grasp of what may and may not be sustainable. However, considerable understanding of how one key framework variable (resource quality) contributes to and is effected by a production process will alone lead us furthest in our advancement of understanding sustainability. Monitoring resource quality and the ability to construct meaningful indicators of resource quality is crucial if we are to understand how to sustain our natural resources. We chose to use an index of resource quality in our framework because in our case it seems well suited to address many of the complicating factors (e.g. heterogeneity in spatial dimensions and temporal dimensions) in a reasonably objective manner. However there are of course some disadvantages and limitations as discussed below.

Spatial complications are related to both resource heterogeneity and resource use. First, the framework and example have shown that a resource is not just a resource, soil is not just soil.
Resource endowments can vary greatly in quality. An index provides a means to aggregate unique measures of important unique characteristics for each endowment in order to capture the quality differences across heterogeneous endowments. In our soil index, heterogeneity is captured in the unique composite measurement of available water capacity, bulk density, organic matter $\mathrm{pH}$ and rooting depth. Secondly, the characteristics that capture the quality of a resource for one use may be different from those for another use. Characteristics may be added to or deleted from an index to create a new proxy of quality for an alternative use. It is expected that one index may be appropriate in examining similar resource uses (for example, soil used for corn or sorghum production). However, the more diverse the resource uses the more likely the need for alternative indices for each use.

The second complication is that in order to assess how natural and anthropogenic activities affect environmental condition, an indicator must trace the change in resource quality over time. Indices allow for the comparison of measurements across any number of time periods and thus can assess environmental condition over time.

Most indicators include some degree of subjectivity. The deliberation of resource policy currently involves more than integration and aggregation of facts. Accurate scientific information, while extensive, is not sufficient to identify the characteristics of quality of all resources and for all uses. To what extent this subjectivity hampers our ability to accurately assess environmental condition or target sustainability varies across resources.

Subjectivity can enter into an index through the choice of resource characteristics or through the techniques used to measure them. For example, we chose a new soil quality index over that offered by Pierce et al. (1983) because regression analysis showed that ours better explained the contribution of soil quality to crop yields (Popp, 1997). Other researchers may have chosen very different inputs or outputs as influenced by their disciplines. 


\section{Conclusion}

This paper reports the development of a framework for evaluating resource management decisions in a production setting. The framework demonstrates that different endowments of resource quality can change over time in different ways. Evaluating changes using substitution, reversibility and uncertainty criteria has produced some general guidelines for managing a resource in a single production process. When applied to an actual resource such as soil we can provide managers with information about which endowments need to be preserved and how risk and uncertainty can effect an organization's choice of input mix for producing an agricultural commodity. Furthermore by revealing the economic and environmental impacts of management production associated with targeting alternative definitions of sustainability we can identify for policy makers when public intervention is needed to achieve some target of sustainability and perhaps, which definitions of sustainability are worth pursuing at all.

However, accurate elicitation of these insights is dependent upon reliable assessment of environmental condition. A reliable assessment is difficult to construct when there is so much complexity in defining, measuring and monitoring resource quality. This research has provided some new insights about index development and use that others may find helpful.

First, reliable assessments will require that indicators can capture differences in quality across resource endowments and resource uses. Secondly, indicators must be able to measure changes in quality levels through natural and human activities over time. Third, subjectivity can exist in: (1) defining sustainability; (2) representing that definition in a production scenario; (3) choosing characteristics for an indicator; and (4) measuring and monitoring those characteristics over time. In each case, subjectivity must be acknowledged and then minimized through performance testing. Finally even as this report reaches its end sustainability remains ambiguous.

\section{Acknowledgements}

The information in this article has been funded wholly or in part by the US Environmental Protection Agency. The views expressed in this paper are those of the author(s) and do not necessarily reflect the views or policies of the US Environmental Protection Agency. The US Government has the right to retain a non-exclusive royalty-free license in and to any copyright covering this article.

\section{References}

Acton, D.F., Gregorich, L.J., 1995. Understanding soil health. In: Acton, D.F., Gregorich, L.J. (Eds.), The Health of Our Soil Toward Sustainable Agriculture in Canada. Center for Land and Biological Resources Research, Research Branch, Agriculture and Agri-Food, Ottawa, pp. 4-8.

Beattie, B.R., Taylor, C.R., 1985. The Economics of Production. Wiley, New York.

Bowman, R.A., Reeder, J.D., Schuman, G.E., 1990. Evaluation of selected soil physical, chemical and biological parameters as indicators of soil productivity. In: Stewart, J.W.B. (Ed.), Soil Quality in Semiarid Agriculture Proceedings of an International Conference as Part of the First Global Agricultural Technology Exposition. University of Saskatchewan, Saskatchewan, pp. 64-70.

Bowman, R., Petersen, M., 1996. Soil organic matter levels in the Central Great Plains. Conservation tillage fact sheet \# 1-96. USDA-ARS and USDA-NRCS, Washington.

Brooke, A., Kendrick, D., Meeraus, A., 1992. Gams User Guide Release 2.25. Scientific Press, San Francisco, CA.

Burt, O., 1981. Farm level economics of soil conservation in the Palouse area of the Northwest. Am. J. Agric. Econ. 63, 83-92.

Clark, J.S., Furton, W.H., 1983. An economic model of soil conservation-depletion. J. Environ. Econ. Manage. 10, 356-370.

Doran, J.W., Parkin, T., 1994. Defining and assessing soil quality. In: Doran, J.W., Coleman, D.C., Bezdicek, D.F., Stewart, B.A. (Eds.), Defining Soil Quality for a Sustainable Environment. SSSA Special Publication Number 35. SSSA, AMA, Madison, pp. 3-21.

Doran, J.W., Sarrantonio, M., Liebig, M.A., 1996. Soil health and sustainability. In: Sparks, D.L. (Ed.), Advances in Agronomy. Academic Press, San Diego, pp. 1-54.

Hartwick, J., 1978. Substitution among exhaustible resources and intergenerational equity. Rev. Econ. Stud. XLV-2, 347-354.

Hoag, D., 1998. The intertemporal impact of soil erosion on non-uniform soil profiles: a new direction in analyzing erosion impacts. Agric. Syst. 56, 415-429. 
Hsaio, C., 1991. Analysis of Panel Data. Econometric Society Monographs Number 11. Cambridge University Press, New York.

Hyatt, D.E., Hoag, D.L., 1997. Environmental condition us value based, an insiders perspective of the United States Environmental Protection Agency's environmental monitoring and assessment program.

Karlen, D.L., Mausbach, M.J., Doran, J.W., Kine, R.G., Harris, R.F., Schuman, G.E., 1997. Soil quality: a concept, definition and framework for evaluation (a guest editorial). Soil Sci. Soc. Am. J. 61, 4-10.

Kiniry, L.N., Scrivner, C.L., Keener, M.E., 1983. A soil productivity index based upon predicted water depletion and root growth. College of Agriculture, Agricultural Experiment Station Research Bulletin 1051. University of Missouri-Columbia, Columbia.

Larson, W.E., Pierce, F.J., 1994. The dynamics of soil quality as a measure of sustainable management. In: Doran, J.W., Coleman, D.C., Bezdicek, D.F., Stewart, B.A. (Eds.), Defining Soil Quality for a Sustainable Environment. SSSA Special Publication Number 35. SSSA, ASA, Madison, pp. 37-52.

Mitchell, G., Griggs, R.H., Benson, V., Williams, J., 1995. The EPIC Model. Environmental Policy Integrated Climate Users Guide. Texas Agricultural Experiment Station, USDA ARS, NRCS, Temple, TX.

Nicholson, W., 1992. Microeconomic Theory Basic Principles and Extensions, 5th ed. Dryden Press, New York.

Olson, K.R., Lal, R., Norton, L.D., 1994. Evaluation of methods to study soil erosion-productivity relationships. J. Soil Wtr. Conserv. 49, 586-590.

Pearce, D., Atkinson, G., 1993. Capital theory and the measurement of sustainable development an indicator of weak sustainability. Ecol. Econ. 8, 103-108.

Pearce, D., Atkinson, G., 1995. Measuring sustainable development. In: Bromley, D. (Ed.), The Handbook of Envi- ronmental Economics. Blackwell, Cambridge, pp. $166-181$.

Pierce, F.J., Larson, W.E., Dowdy, R.H., Graham, W.A.P., 1983. Productivity of soils: assessing long-term changes due to erosion. J. Soil Wtr. Conserv. 38, 39-44.

Pieri, C., 1995. Long term experiments on soil management in semi-arid Francophone Africa. In: Lal, R., Stewart, B.A. (Eds.), Soil Management Experimental Basis for Sustainability and Environmental Quality. Lewis, Boca Raton, FL, pp. 225-266.

Popp, J.S.H., 1997. In search of sustainability: the economic, social and environmental consequences of natural resource management, a case study of soil conservation in the United States. Ph.D. Dissertation. Colorado State University, Fort Collins.

Romig, D.E., Garlynd, M.J., Harris, R.F., McSweeney, K., 1995. How farmers assess soil health and soil quality. J. Soil Wtr. Conserv. 50, 229-236.

Saliba, B.C., 1985. Soil productivity and farmers' erosion control incentives — a dynamic modeling approach. West. J. Agric. Econ. 10, 354-364.

Segarra, E., Taylor, D.B., 1987. Farm level dynamic analysis of soil conservation: an application to the Piedmont area of Virginia. South. J. Agric. Econ. 19, 61-73.

Solow, R., 1974. The economics of resources or the resources of economics. Am. Econ. Rev. 64, 1-13.

United States Department of Agriculture, Natural Resources Conservation Service (USDA, NRCS), 1996. Indicators for soil quality evaluation. Soil Quality Information Sheet. US Department of Agriculture, Washington.

United States Department of Agriculture, Natural Resources Conservation Service (USDA, NRCS), 1995. Soil quality. NRCS/RCA Issue Brief 5. US Department of Agriculture, Washington.

Varian, H.R., 1992. Microeconomic Analysis, 3rd ed. W.W. Norton, New York. 